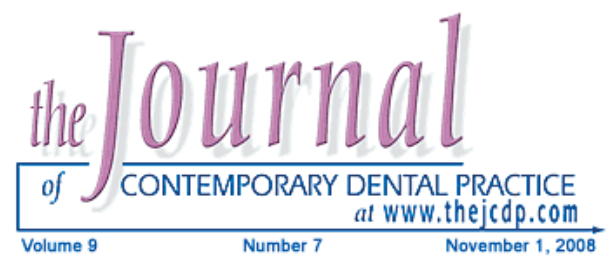

\title{
Clinical Evaluation of a Resin-based Desensitizing Agent and Self-etching Adhesive on Reduction of Postoperative Sensitivity of Amalgam Restorations
}

Hila Hajizadeh, DDS, MS; Majid Akbari, DDS, MS;

Marjaneh Ghavamnasiri, DDS, MS; Sara Abedini, DDS

Aim: The aim of this randomized, double blind clinical trial was to compare three lining materials (Adper Prompt L-Pop, VivaSens, and Copalite) versus unlined restorations on postoperative cold sensitivity of class I amalgam restorations.

Methods and Materials: Potential subjects were screened for the presence of four initial class I carious lesions on posterior teeth. Each tooth was assigned to treatments according to a randomized block design. After cavity preparation, teeth were lined with either VivaSens, Adper Prompt L-Pop, or Copalite, and one tooth remained unlined and served as a control. The cavities were filled with high copper amalgam (Oralloy). The time taken for a subject to respond to a standardized cold stimulus (CRM) was recorded at baseline, 24 hours, one week, and one month after treatment. Participants filled out a self-report questionnaire at each time point. Data was gathered by analysis of variance (ANOVA) and Duncan Multiple Comparisons tests $(\alpha=0.05)$.

Results: Twenty subjects participated in this study. Comparisons within each group found no significant reduction in mean CRM for the Adper Prompt L-Pop group ( $P>0.05)$, but a significant difference in mean CRM for the VivaSens group was observed at one week and one month intervals after restoration $(P<0.05)$. Copalite and the unlined groups showed significant mean CRM reductions after one day $(P<0.05)$. No significant differences between groups receiving Adper Prompt L-Pop and Copalite were found at any time point $(P>0.05)$.

(C) Seer Publishing 
VivaSens showed more cold sensitivity than Adper Prompt L-Pop at one week and one month recalls $(P<0.05)$, while the most cold sensitivity was found in the unlined group.

Conclusion: Adper Prompt L-Pop and Copalite reduced postoperative sensitivity to cold more than VivaSens and unlined groups at all assessment time points, 24 hours, one week, and one-month post treatment. The subjects receiving Copalite, VivaSens, and unlined restorations experienced greater sensitivity to cold at one month compared to baseline, while subjects receiving the Adper Prompt L-Pop liner experienced no greater sensitivity to cold from baseline to one month.

Clinical Significance: Adper Prompt L-Pop as a liner under spherical high copper amalgam successfully reduced cold postoperative sensitivity.

Keywords: Randomized clinical trial, amalgam, resin-based desensitizing agent, cavity varnish, all-in-one adhesive system

Citation: Hajizadeh H, Akbari M, Ghavamnasiri M, Abedini S. Clinical Evaluation of a Resin-based Desensitizing Agent and Self-etching Adhesive on Reduction of Postoperative Sensitivity of Amalgam Restorations. J Contemp Dent Pract 2008 November; (9)7:009-016.

\section{Introduction}

Dental amalgam has been used successfully for more than 170 years as a restorative material. It has several advantages, such as easy manipulation and placement, good wear resistance, low technique sensitivity, acceptable life expectancy, and low cost. ${ }^{1}$ However, this material lacks adhesion to tooth structure. Many dental practitioners use an adhesive agent to bond amalgam to tooth structure. The potential advantage of this procedure, as suggested by in vitro test results, is to reduce the microleakage which could lead to a reduction in postoperative sensitivity. ${ }^{2}$ The presence of pain after dental

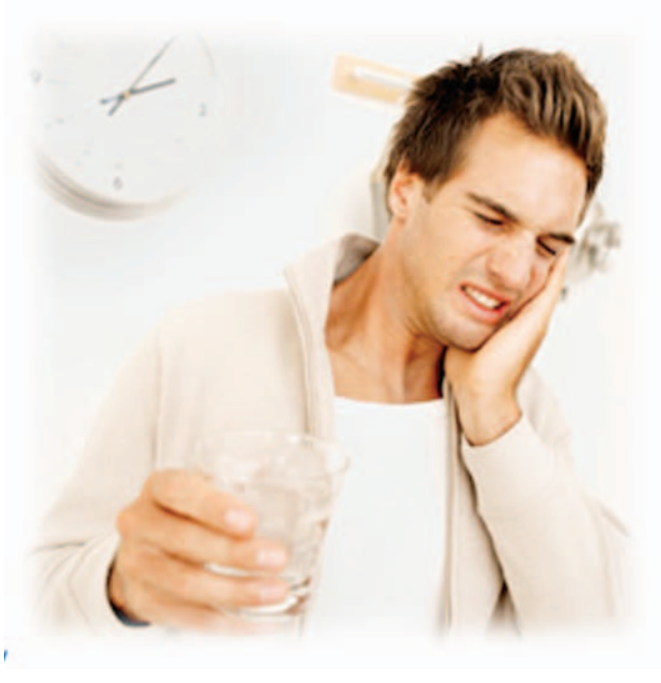

procedures may be of concern to patients and has an adverse impact on patient satisfaction. Several investigations have evaluated postoperative sensitivity and estimates of the prevalence and severity of postoperative pain vary substantially. In a randomized, clinical control trial conducted by Browning ${ }^{3} 50 \%$ of participants reported mild to moderate sensitivity to cold after placement of amalgam restorations that included use of conventional liners and cavity varnishes. They found no significant reduction in the mean cold response measurement (CRM) for the group receiving Amalgambond Plus under amalgam restorations. The authors concluded subjects in the Amalgambond Plus group experienced no extra sensitivity to cold at one week postoperative than they did at base line, while the subjects in the Copalite group showed more sensitivity between these two time intervals. ${ }^{3}$

Mahler and Engle, ${ }^{2}$ in a three year clinical study, demonstrated amalgam bonding for traditional class I and class II restorations, admixed or spherical amalgam, had no effect on postoperative sensitivity. Browning ${ }^{4}$ found Opti Bond adhesive liner used under amalgam restorations was less sensitive to cold than conventional liners and bases. A previous study comparing postoperative sensitivity of class $\mathrm{V}$ caries restored by amalgam and lined by either Copalite or Dentin Bloc cavity 
liner found Dentin Bloc liner more effective than Copalite in reducing short-term postoperative sensitivity. ${ }^{5}$ A short-term clinical assessment by Gordon ${ }^{6}$ concluded Scotchbond MP and Copalite under amalgam restorations following treatment of primary class I and II carious lesions exhibited initial sensitivity which lasted up to 30 days. Gordon $^{7}$ also showed there was no correlation between different dentin treatments with cavity depths in respect to tooth sensitivity.

A short-term clinical study evaluating postoperative sensitivity of amalgam using Scotchbond MP and copal varnish found no significant difference between the two cavity lining materials. ${ }^{8}$ Finally, in a recent study conducted by Al-Omar ${ }^{9}$ the postoperative cold sensitivity of class I and II amalgam restorations lined with calcium hydroxide, Single Bond, Vitrebond, Consepsis, and no treatment was evaluated. That study concluded postoperative sensitivity beyond 30 days is neither affected by the method of cavity treatment nor by depth of the lesion, although in the shorter term these factors influence the postoperative sensitivity.

The aim of this randomized, double blind clinical trial was to compare three lining materials, Adper Prompt L-Pop (3M ESPE, St. Paul, MN, USA), VivaSens (Ivoclar/Vivadent, Schaan, Lichtenshtain), Copalite varnish (Cooley \& Cooley Ltd., Houston, TX, USA), and unlined restorations, on postoperative cold sensitivity of Class I amalgam restorations.

\section{Methods and Materials}

Twenty adult subjects, 15 to 25 years old, with class I carious lesions were recruited from Mashhad Dental School. The Institutional Review Board for Human Research at Mashhad University of Medical Sciences reviewed and ethically approved this investigation.

Participants were informed about the nature of the study; they would receive four amalgam fillings with three different liners and one without any liner. A written consent was also required before starting any treatment.

Each potential subject was screened to identify four initial class I carious lesions on vital molar or premolar teeth. Exclusion criteria included abrasion or other defects on the teeth and any previous pain reported for the selected teeth. Vitality tests and bitewing radiographs were taken for each subject to confirm the candidate's teeth were vital and free of proximal caries.

An alginate impression was also taken on the first appointment. A custom stent was then fabricated from the model. Teeth selected for treatment were blocked out on the model with 28-gauge green wax (KerrLab Co., Orange, CA, USA). The blockout extended from the mesial to the distal line angles and from the cervical on the facial, across the occlusal to the cervical on the lingual surface of the tooth. The stent was then fabricated using Triad VLC Resin (Dentsply, York, PA, USA). The use of green wax blockout created a reservoir for cold water around the treated tooth, while other teeth were in close contact with the impression material. An occlusal opening was made in the stent to allow cold water injection into the reservoir.

At baseline, prior to treatment, CRM was recorded to the nearest tenth of a second for each test tooth. The water, which had been stored in disposable syringes, was injected into the stent through the occlusal opening with a plastic cannula at a constant temperature of $5^{\circ} \mathrm{C}$ to obtain the measurement. The subject was given a digital stopwatch, which started when operator said "go" and stopped when a definite cold sensation was felt from the tooth. Wording remained consistent throughout the project.

The subject was then anesthetized, the tooth was isolated with a rubber dam, and the class I cavity was prepared. If the depth of cavity was deeper than $2 \mathrm{~mm}$, the tooth was filled and excluded from the study. This study attempted to select one tooth in each quadrant. Each subject contributed four teeth, which were randomized to receive a lining material (Copalite, Adper Prompt L-Pop, or VivaSens) or no liner (Table 1).

A block randomization schedule was used for the treatment assignment to teeth (Table 2). The schedule was prepared in advance and recorded on cards. Each card had a chart of four quadrants. Four different versions of this chart were made. In the first version "Copalite" was marked on the upper right, "Adper Prompt 
Table 1. Protocol specified and manufacturers for different liners.

\begin{tabular}{|c|c|c|c|}
\hline $\begin{array}{l}\text { Experimental } \\
\text { Groups }\end{array}$ & Manufacturer & Ingredients & Instruction \\
\hline Copalite & $\begin{array}{l}\text { Cooley \& Cooley Ltd. } \\
\text { USA }\end{array}$ & $\begin{array}{l}\text { Copal Varnish } \\
\text { Chloroform } \\
\text { Acetone }\end{array}$ & $\begin{array}{l}\text { 1. Copalite was applied to } \\
\text { enamel and dentin surfaces. } \\
\text { 2. After each coat, the cavity } \\
\text { was gently air dried. }\end{array}$ \\
\hline $\begin{array}{l}\text { Adper Prompt } \\
\text { L-Pop }\end{array}$ & $\begin{array}{l}\text { 3M ESPE } \\
\text { USA }\end{array}$ & $\begin{array}{l}\text { Liquid } 1 \text { (red blister): } \\
\text { Methacrylated phosphoric esters, } \\
\text { Bis-GMA, Initiators based on } \\
\text { camphorquinone, Stabilizers } \\
\text { Liquid } 2 \text { (yellow blister): } \\
\text { Water, 2-Hydroxyethyl methacrylate } \\
\text { (HEMA), Polyalkenoic acid, } \\
\text { Stabilizers }\end{array}$ & $\begin{array}{l}\text { 1. Adper Prompt L-Pop was } \\
\text { activated by mixing the } 2 \\
\text { components. } \\
\text { 2. It was applied to the cavity for } \\
15 \text { seconds then thinned with } \\
\text { a gentle stream of air. } \\
\text { 3. Light-curing was done for } 10 \\
\text { seconds. }\end{array}$ \\
\hline VivaSens & $\begin{array}{l}\text { IvoclarNivadent } \\
\text { Lichtenshtain }\end{array}$ & $\begin{array}{l}\text { Liquid: } \\
\text { Ethanol, water and hydroxypropyl } \\
\text { cellulose, polyethylenglycol } \\
\text { dimethacrylate, Methacrylate } \\
\text { modified polyacrylic acid, potassium } \\
\text { fluoride, Aroma } \\
\text { Microbrush: } \\
\text { Phosphonic acid methacrylate }\end{array}$ & $\begin{array}{l}\text { 1. The white applicator brush } \\
\text { was dipped into the chamber } \\
\text { containing the VivaSens } \\
\text { liquid. } \\
\text { 2. The liquid was mix with the } \\
\text { ingredients contained on the } \\
\text { applicator brush. } \\
\text { 3. The cavity preparation was } \\
\text { rinsed and dried } \\
\text { 4. VivaSens was applied to } \\
\text { enamel and dentin surfaces } \\
\text { 5. After } 10 \text { seconds, it was } \\
\text { gently air dried. }\end{array}$ \\
\hline Unlined & - & - & No liner placed \\
\hline
\end{tabular}

Table 2. Randomization in teeth.

\begin{tabular}{|l|c|c|}
\hline \multicolumn{1}{|c|}{ Lining Material } & $\begin{array}{c}\text { Bicuspid } \\
(\mathbf{n = 2 4 )}\end{array}$ & $\begin{array}{c}\text { Molar } \\
(\mathbf{n = 5 6})\end{array}$ \\
\hline Copalite & 5 & 15 \\
\hline Adper Prompt L-Pop & 6 & 14 \\
\hline VivaSens & 7 & 13 \\
\hline Unlined & 6 & 14 \\
\hline
\end{tabular}


L-Pop" on the upper left, "VivaSens" on lower left, and "Unlined" was marked on the lower right. In the second version different liners were moved clockwise among the quadrants. Therefore, Copalite was moved to upper left and Adper Prompt L-Pop was moved to lower left and this method was followed routinely to complete 20 cards. Each card was sealed in an envelope and randomly assigned to each participant.

The cards were opened at the treatment appointment by the operator. Both evaluator and subject were blinded to treatment group assignment throughout the study. One operator performed all of the operative procedures. The evaluator recorded all of the CRM data.
Restorative treatment procedures for all teeth followed a strict protocol (Table 1). Cavities were filled with a high copper amalgam material, Oralloy (Colten/Whaledent, Altstätten, Switzerland).

Subjects were instructed to fill out a series of three self-report questionnaires at 24 hours, seven days, and one month following treatment. The questionnaires recorded cold sensitivity and eight other common postoperative complaints the subjects may experience. Four different rating categories (no pain, mild, moderate, and severe) were used in the questionnaires to determine postoperative sensitivity to cold. CRM data at three post restoration time points were recorded exactly in the same manner as the baseline CRM.

Table 3. Cold response measurements.

\begin{tabular}{|c|c|c|c|c|c|}
\hline \multirow{2}{*}{ Group } & \multirow{2}{*}{ Time Interval } & \multirow{2}{*}{ Mean } & \multirow{2}{*}{$\begin{array}{l}\text { Standard } \\
\text { Deviation }\end{array}$} & \multicolumn{2}{|c|}{$\begin{array}{l}\text { Significant Difference } \\
\qquad(\alpha=0.05)\end{array}$} \\
\hline & & & & Within Group & Between Groups \\
\hline \multirow{4}{*}{ Copalite } & Baseline & 6.4040 & 4.6455 & $\alpha$ & $\alpha$ \\
\hline & 24 hours & 3.5985 & 3.3256 & $\beta$ & $\alpha$ \\
\hline & 1 week & 3.1358 & 2.4773 & B & $\alpha$ \\
\hline & 1 month & 3.6090 & 6.0095 & $B$ & $\alpha$ \\
\hline \multirow{4}{*}{$\begin{array}{l}\text { Adper Prompt } \\
\text { L-Pop }\end{array}$} & Baseline & 4.8150 & 3.1404 & $\alpha$ & $\alpha$ \\
\hline & 24 hours & 4.9855 & 5.0267 & $\alpha$ & $\alpha$ \\
\hline & 1 week & 3.6965 & 2.0191 & $\alpha$ & $\alpha$ \\
\hline & 1 month & 4.1960 & 3.0934 & $\alpha$ & $\alpha$ \\
\hline \multirow{4}{*}{ VivaSens } & Baseline & 5.7720 & 3.1717 & $\alpha$ & $\alpha$ \\
\hline & 24 hours & 4.2325 & 5.8650 & $\alpha$ & $\alpha$ \\
\hline & 1 week & 2.5510 & 1.8838 & $B$ & $B$ \\
\hline & 1 month & 2.7910 & 2.0965 & $\beta$ & $\beta$ \\
\hline \multirow{4}{*}{ Unlined } & Baseline & 5.4655 & 3.4383 & $\alpha$ & $\alpha$ \\
\hline & 24 hours & 2.4080 & 1.6477 & B & B \\
\hline & 1 week & 2.4300 & 1.4905 & $\beta$ & $\beta$ \\
\hline & 1 month & 2.8770 & 2.1827 & B & $B$ \\
\hline
\end{tabular}


Data Analysis

The primary outcome measure used in this study was the CRM measured to the nearest tenth of a second as the time it took the subject to recognize tooth sensitivity in the test teeth. A shorter CRM indicates a more cold-sensitive tooth, while a longer CRM indicates a less cold sensitive tooth. Data were analyzed using one way analysis of variance (ANOVA) and Duncan Multiple Comparisons test $(\alpha=0.05)$.

\section{Results}

Mean CRM for each group are presented in Table 3.

Comparisons within each treatment group (Figure 1) found a significant difference between the CRM recorded at baseline and each time interval (24 hours, one week, and one month) for unlined teeth and Copalite lined teeth $(P<0.05)$. Teeth lined with VivaSens showed a statistically significant difference between the CRM recorded

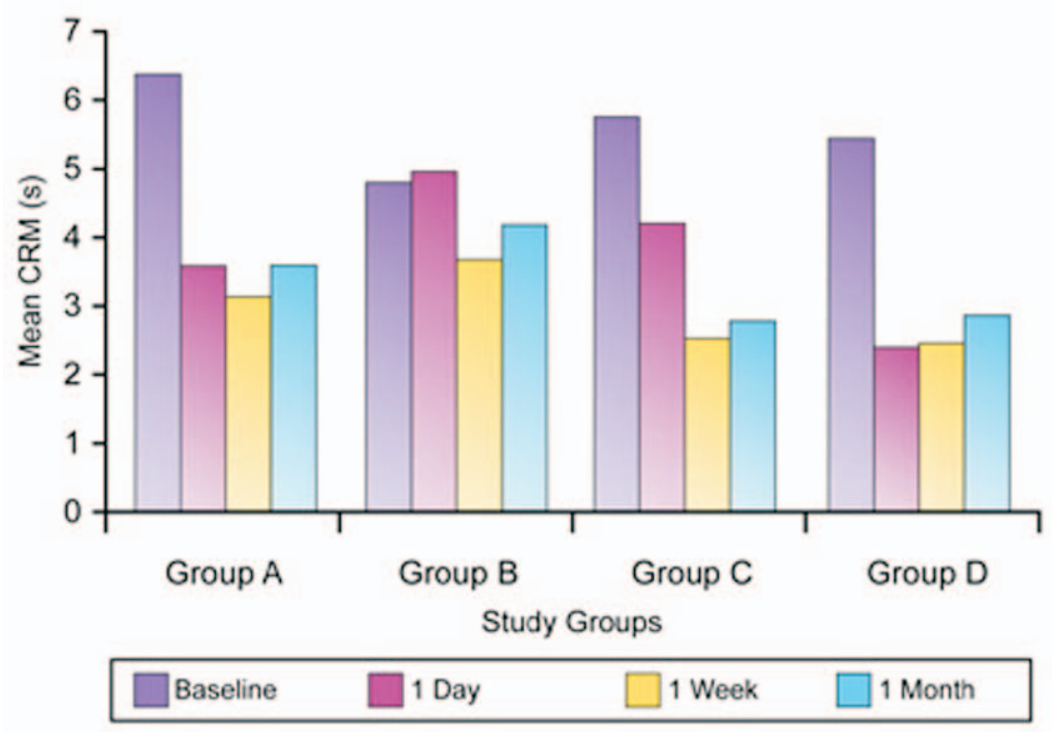

Figure 1. Mean CRM in different groups.

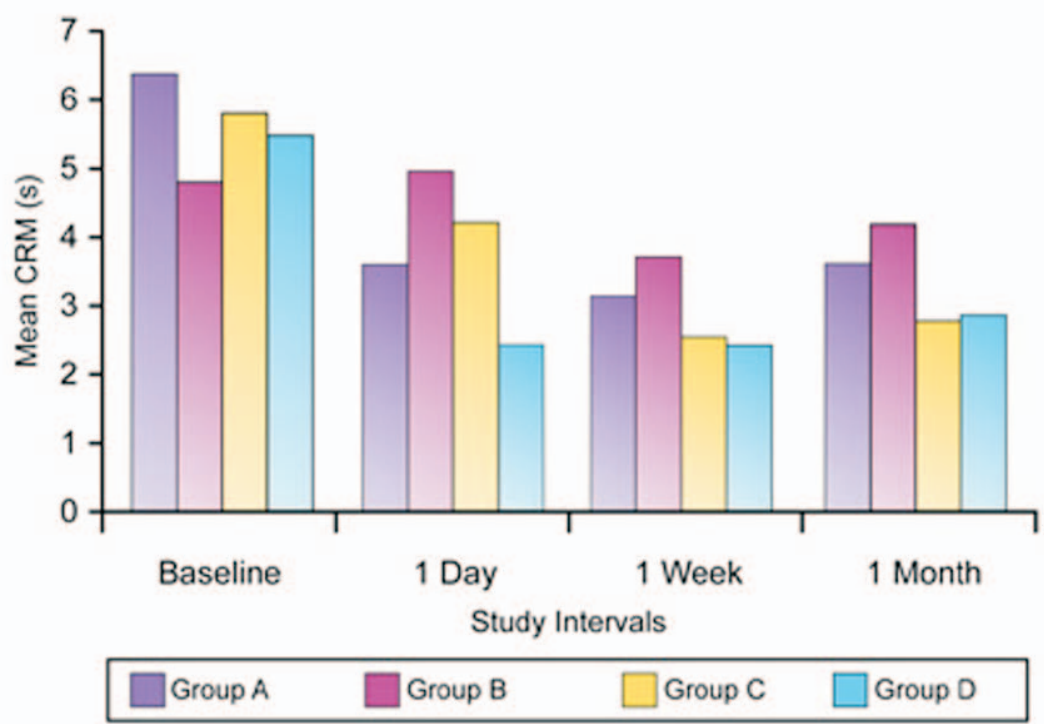

Figure 2. Mean CRM in different intervals. 
at baseline, 24 hours, one week, and one month after treatment $(P<0.05)$. There was no significant difference between the mean CRM recorded at different time intervals for the teeth lined with Adper Prompt L-Pop ( $\mathrm{P}>0.05)$.

Mean CRM comparisons between lined and unlined teeth showed there was no significant differences at baseline $(P>0.05)$ (Figure 2). At the first recall, 24 hours, a significant difference was found between the unlined teeth compared to the three treated teeth $(P<0.05)$. Unlined teeth showed a smaller mean CRM.

At the one week and one month recall, significant differences were found between teeth lined with VivaSens and unlined teeth with either Copalite or Adper Prompt L-Pop $(\mathrm{P}<0.05)$. Adper Prompt L-Pop and Copalite varnish showed less postoperative cold sensitivity (Table 3 and Figure 2).

Cold sensitivity measured by the self-report questionnaires was not significantly different at 24 hours, one week, or one month after treatment for any group or interval $(P>0.05)$. It was also noted a majority of subjects reported no pain with exposure to a cold stimulus.

\section{Discussion}

The results of this study support the use of amalgam restorations lined with adhesive materials shows less postoperative sensitivity to cold. ${ }^{3-8}$ Although these materials seal the dentinal tubules, they might not be a suitable thermal insulator due to their thickness. ${ }^{10}$ This project investigated a self etching adhesive

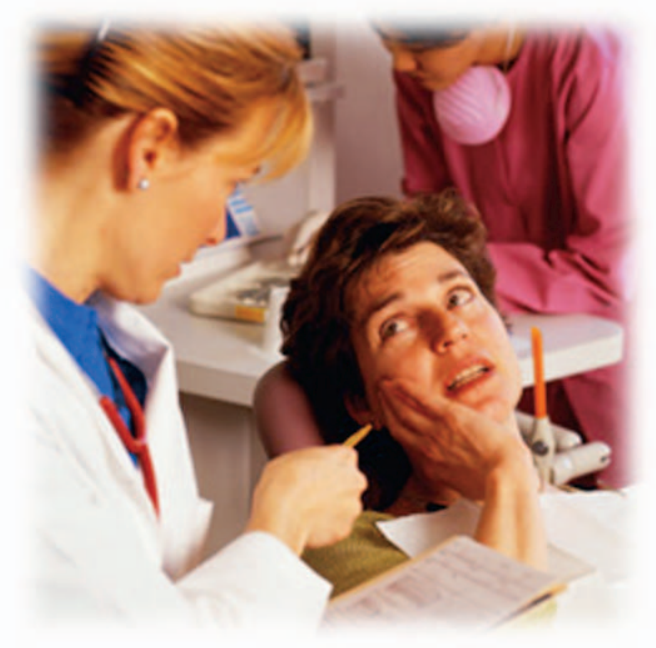

material (Adper Prompt L-Pop) with two other lining materials. While the differences found between linings might be product specific, other possibilities need to be considered as well.

This study showed a majority of subjects reported no pain with exposure to a cold stimulus via selfreporting. Among those subjects experiencing some pain, many reported the pain to be minor. These results were similar to the findings of Browning. ${ }^{4}$ Thus, practitioners asking patients about postoperative sensitivity often get a report of no pain or very little pain.

Adper Prompt L-Pop demonstrated the greatest effect on postoperative cold sensitivity with no significant differences found at baseline and at the three postoperative time intervals with this adhesive material. Adper Prompt L-Pop is a selfetching primer adhesive system allowing both mechanical and chemical bonding to dentin. In addition, the manufacturer describes Adper Prompt L-Pop as having the following advantages: fewer steps with less introduction of error, fresh activation of product with each application, and reduction of postoperative sensitivity. Recent studies, however, showed Adper Prompt L-Pop did not have acceptable sealing capability. ${ }^{11-13}$

In the present study there was no significant difference in cold postoperative sensitivity between Adper Prompt L-Pop and Copalite at the one week and one month recalls. It seems there is no clear evidence resin adhesive lined amalgam restorations are superior to conventional basing and lining practices. ${ }^{14}$ This conclusion was similar to the results of some previous studies. ${ }^{4,6,8}$

Comparing the four different time intervals, the greatest reduction in CRM was observed at one week and one-month intervals in teeth treated with VivaSens. VivaSens is a protective or resin based desensitizing varnish and contains phosphonic acid and methacrylate modified polyacrylic acid form tags that can obstruct dentinal tubules. ${ }^{15}$ This varnish leads to a coverage and closure of open dentinal tubules resulting in mechanical obliteration of the dentinal tubules or precipitation of calcium fluoride or proteins. ${ }^{16}$ VivaSens lined teeth had significantly higher cold postoperative sensitivity at one week and one month recall in comparison with Copalite 
and Adper Prompt L-Pop treated teeth. This result is probably due to more solubility and less adhesion of VivaSens. It seems the VivaSens peeled off from the interface of amalgam restorations after a few days. Although, Betke ${ }^{16}$ claimed no changes in dentin moisture were observed after application of VivaSens.

Mahler and Nelson ${ }^{17}$ demonstrated admixed alloys have been shown to seal against microleakage better than spherical alloys. Furthermore, microleakage considered to be a significant cause of postoperative sensitivity due to the hydrodynamic effect has been shown to be related to setting dimensional changes and amalgam mix plasticity. ${ }^{2}$ Microleakage increases with more setting contraction and lower mix plasticity. ${ }^{18}$ In general, spherical particle alloys exhibit negative characteristics in regard to each of these factors. The postoperative sensitivity to cold may, in part, result from the type of amalgam alloy used.
Amalgam restorations with and without copal varnish liners have a long history of clinical success, and the long-term success of adhesive systems lined amalgam restorations will depend on additional clinical data.

\section{Conclusion \\ 1. Adper Prompt L-Pop and Copalite lining materials reduced the postoperative cold sensitivity more than VivaSens and unlined treated teeth at all time intervals. \\ 2. Teeth lined with Adper Prompt L-Pop experienced no more sensitivity to cold at one month than they did at baseline, while the unlined teeth and the teeth lined with Copalite or VivaSens showed an increasing sensitivity to cold over time.}

\section{Clinical Significance \\ Use of Adper Prompt L-Pop as a liner under spherical high copper amalgam successfully reduced cold postoperative sensitivity.}




\section{References}

1. Cenci MS, Piva E, Potrich F, Formolo E, Demarco FF, Powers JM. Microleakage in bonded amalgam restorations using different adhesive materials. Braz Dent J 2004 15(1):13-8.

2. Mahler DB, Engle JH. Clinical evaluation of amalgam bonding in Class I and II restorations. J Am Dent Assoc 2000 Jan;131(1):43-9.

3. Browning WD, Johnson WW, Gregory PN. Reduction of postoperative pain: a double-blind, randomized clinical trial. J Am Dent Assoc 1997 Dec;128(12):1661-7.

4. Browning WD, Johnson WW, Gregory PN. Postoperative pain following bonded amalgam restorations. Oper Dent 1997 Mar;22(2):66-71.

5. Schwartz RS, Conn LJ, Jr., Haveman CW. Clinical evaluation of two desensitizing agents for use under Class 5 silver amalgam restorations. J Prosthet Dent 1998 Sep;80(3):269-73.

6. Gordan VV, Mjor IA, Hucke RD, Smith GE. Effect of different liner treatments on postoperative sensitivity of amalgam restorations. Quintessence Int 1999 Jan;30(1):55-9.

7. Gordan VV, Mjor IA, Moorhead JE. Amalgam restorations: postoperative sensitivity as a function of liner treatment and cavity depth. Oper Dent 1999 Nov;24(6):377-83.

8. Kennington LB, Davis RD, Murchison DF, Langenderfer WR. Short-term clinical evaluation of postoperative sensitivity with bonded amalgams. Am J Dent 1998 Aug;11(4):177-80.

9. Al Omari WM, Al Omari QD, Omar R. Effect of cavity disinfection on postoperative sensitivity associated with amalgam restorations. Oper Dent 2006 Mar;31(2):165-70.

10. Roberson TM, Heymann HO. Sturdevant's Art and Science of Operative Dentistry. 5 ed. St. Louis: Mosby; 2006. p. 311.

11. Stockton LW, Tsang ST. Microleakage of Class II posterior composite restorations with gingival margins placed entirely within dentin. J Can Dent Assoc 2007 Apr;73(3):255.

12. Brackett WW, Covey DA, St GH, Jr. One-year clinical performance of a self-etching adhesive in class V resin composites cured by two methods. Oper Dent 2002 May;27(3):218-22.

13. Pontes DG, de Melo AT, Monnerat AF. Microleakage of new all-in-one adhesive systems on dentinal and enamel margins. Quintessence Int 2002 Feb;33(2):136-9.

14. Moore DS, Johnson WW, Kaplan I. A comparison of amalgam microleakage with a 4-META liner and copal varnish. Int J Prosthodont 1995 Sep;8(5):461-6.

15. Camps J, About I, Van Meerbeek B, Franquin JC. Efficiency and cytotoxicity of resin-based desensitizing agents. Am J Dent 2002 Oct;15(5):300-4.

16. Betke H, Kahler E, Reitz A, Hartmann G, Lennon A, Attin T. Influence of bleaching agents and desensitizing varnishes on the water content of dentin. Oper Dent 2006 Sep;31(5):536-42.

17. Mahler DB, Nelson LW. Sensitivity answers sought in amalgam alloy microleakage study. J Am Dent Assoc 1994 Mar;125(3):282-8.

18. Mahler DB, Adey JD. All factors related to the microleakage of amalgam alloys (abstract 1494). J Dent Res 1997;76:200.

\section{About the Authors}

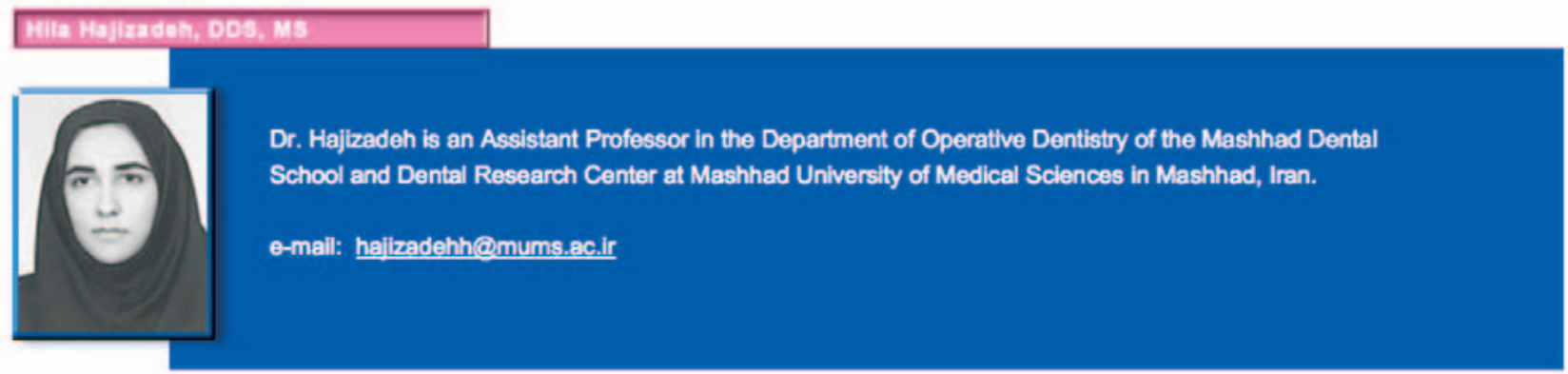



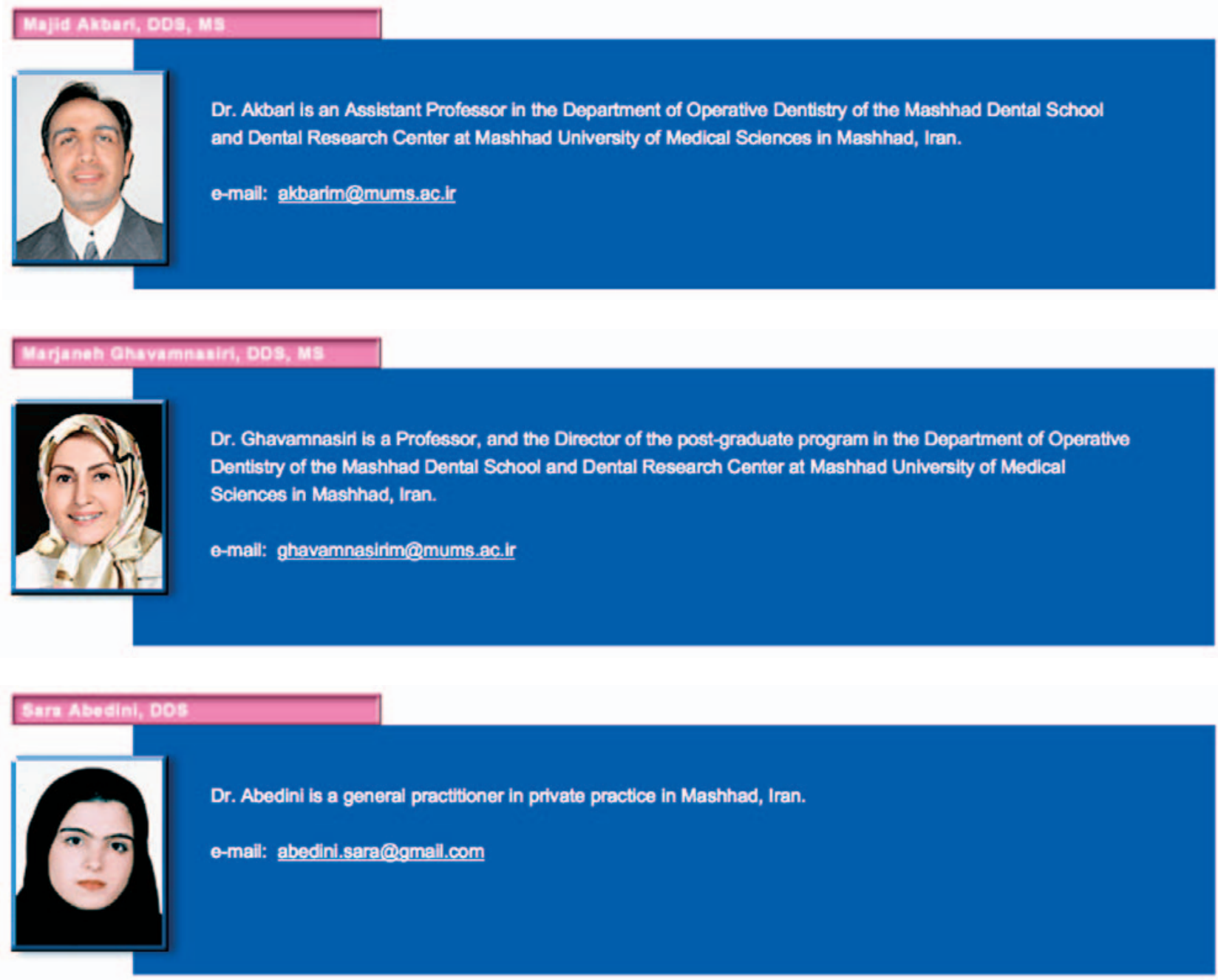

\section{Acknowledgements}

This study was financially supported and approved by the Ethical Committee of Research Council at Mashhad University of Medical Sciences, Mashhad, Iran.

The authors would like to express their sincere appreciation to Taghi Mirmostafaee Ferdowsi, University of Mashhad, Iran, for performing the statistical analysis of the present study. 